\title{
Correlation of furfural and moisture content with age of transformers
}

\begin{abstract}
This paper is aimed at analysis of correlation between age of $132 / 33 \mathrm{kV}$ and $33 / 11 \mathrm{kV}$ transformers with furfural concentration and carbon oxides content of oil. Also, the correlation of moisture content and relative humidity of oil/paper insulation system with furfural concentration of oil is investigated. The secondary data was obtained from the raw data of research studies which have been done in Malaysia on inservice power transformers. As a result, it is not only confirmed that furfural content in the oil was increased by increasing moisture content of the oil, but also there is a good correlation and significant relationship between furfural concentration of the oil and relative humidity of oil/paper insulation system. Also, descriptive statistics such as mean, standard deviation and normal distribution of furfural and moisture content per year of service of transformers described the level of evolution of moisture and furfural for these transformers at normal temperature.
\end{abstract}

Keyword: Transformers; Furfural; Moisture content 